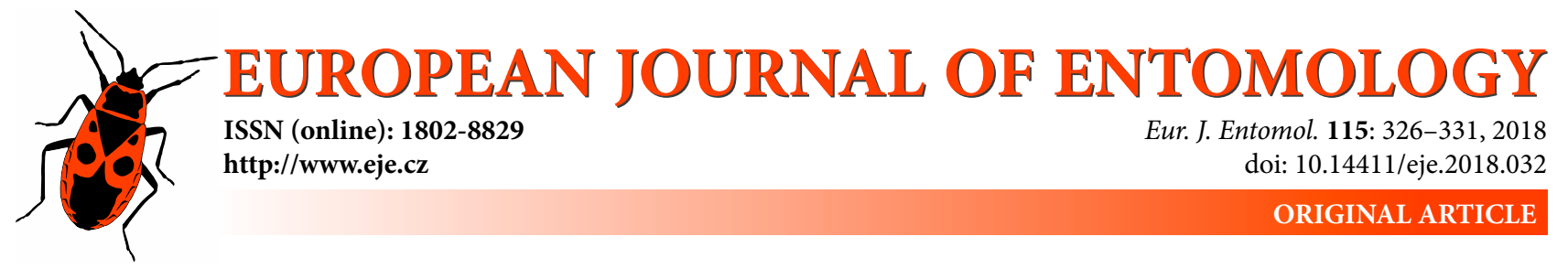

\title{
Temperature-dependent functional response of Aenasius bambawalei (Hymenoptera: Encyrtidae) to different population densities of the cotton mealybug Phenacoccus solenopsis (Hemiptera: Pseudococcidae)
}

\author{
RAZIEH JOODAKI ${ }^{1}$, NOOSHIN ZANDI-SOHANI ${ }^{1, *}$, SARA ZARGHAMI ${ }^{2}$ and FATEMEH YARAHMADI ${ }^{1}$ \\ 1 Department of Plant Protection, Faculty of Agriculture, Khuzestan Agricultural Sciences and Natural Resources University, \\ Mollasani, Iran; e-mails: r.joodaki.3@gmail.com, nzandisohani@yahoo.com, zandi@ramin.ac.ir, yarahmadi@ramin.ac.ir \\ ${ }^{2}$ Department of Plant Protection, Faculty of Agriculture, Shahid Chamran University, Ahvaz, Iran; \\ e-mail: sar.zarghami@gmail.com
}

Key words. Hymenoptera, Encyrtidae, Aenasius bambawalei, Hemiptera, Pseudococcidae, Phenacoccus solenopsis, attack rate, biological control, handling time, parasitoid, cotton mealybug, searching efficiency

\begin{abstract}
The functional response of Aenasius bambawalei Hayat (Hymenoptera: Encyrtidae) to different population densities of Phenacoccus solenopsis Tinsley (Hemiptera: Pseudococcidae) was investigated under laboratory conditions of $65 \pm 5 \%$ R.H., a photoperiod of $14 \mathrm{~L}: 10 \mathrm{D}$ and at temperatures of 25,30 and $35 \pm 1{ }^{\circ} \mathrm{C}$. Two, 4, 6, 8, 16, 32 and 64 third instar nymphs of $P$. solenopsis were exposed to newly emerged mated female parasitoids for $24 \mathrm{~h}$. The parasitoid exhibited a type II functional response at all temperatures. The searching efficiencies $(a)$ and handling times $\left(T_{h}\right)$ were $0.1818 \mathrm{~h}^{-1}$ and $5.0012 \mathrm{~h}$ at $25^{\circ} \mathrm{C}, 0.1382 \mathrm{~h}^{-1}$ and $3.2807 \mathrm{~h}$ at $30^{\circ} \mathrm{C}$, and $0.2097 \mathrm{~h}^{-1}$ and $2.3635 \mathrm{~h}$ at $35^{\circ} \mathrm{C}$, respectively. The maximum attack rates $\left(\mathrm{T} / \mathrm{T}_{\mathrm{h}}\right.$ ) were $4.8,7.3$ and 10.2 nymphs at 25,30 and $35^{\circ} \mathrm{C}$, respectively. This indicates that $A$. bambawalei is more likely to be an effective biological control agent of $P$. solenopsis in warm seasons.
\end{abstract}

\section{INTRODUCTION}

The cotton mealybug, Phenacoccus solenopsis Tinsley (Hemiptera: Pseudococcidae), a new imported pest in Iran, is one of the most important cosmopolitan pests (Hodgson et al., 2008). This species is native to North America and was reported for the first time in Iran in the Hormozgan province on Hibiscus rosa-sinensis, in January 2009 (Moghaddam \& Bagheri, 2010). Currently, 219 species of plants belonging to 70 families are recorded as its host plants in Khuzestan province and on Kish Island, Iran (Mossadegh et al., 2015). This species is reported from South America, Carribean, Pakistan, North-western India, Thailand, Taiwan, China and West Africa (Williams \& Granara de Willink, 1992; Hodgson et al., 2008; Wang et al., 2010). According to a CLIMEX model of the distribution of P. solenopsis worldwide, tropical regions around the world are highly suitable for the growth and development of this species (Wang et al., 2010). Early symptoms of an attack include white and cottony insects on the buds, main stem and branches at the top of plants (Ram \& Saini, 2010). This pest is able to severely reduce photosynthesis by feeding on phloem sap and excreting honeydew, which results in a black sooty mold covering the top of the plant (Prabhakar et al., 2013). Seriously damaged plants dessicate (Ram \& Saini, 2010).

Due to the concealed habit of mealybugs and the waxy substance that protects their nymphs and adults, insecticides are rarely effective in controlling them (Kumar et al., 2009). For such pests, classical and augmentative biological control is thought to be a more appropriate means of control (Tanwar et al., 2011). Thirty species of natural enemies are recorded associated with $P$. solenopsis in the Khuzestan province, Iran. Some of which are predators belonging to the families Coccinellidae, Chrysopidae and Cecidomyidae and some are parasitoids belonging to the family Encyrtidae (Mossadegh et al., 2015). As most of the predators are polyphagous they are usually less effective than the parasitoids (Kumar et al., 2009). The solitary endoparasitoid, Aenasius bambawalei Hayat (Hymenoptera: Encyrtidae), is a primary parasitoid of $P$. solenopsis in different parts of the world like India (Kumar et al., 2009; Ram \& Saini, 2010; Tanwar et al., 2011), southern China

\footnotetext{
* Corresponding author, e-mails: nzandisohani@yahoo.com, zandi@ramin.ac.ir
} 
(Feng et al., 2014), Pakistan (Bodlah et al., 2010) and Iran (Mossadegh et al., 2015). In Southwestern Iran, the percentage parasitism of $P$. solenopsis by $A$. bambawalei was up to $95 \%$ in 2012 when insecticides were not used to control this pest (Mossadegh et al., 2015).

One of the parasitoid attributes correlated with its success in biological control is the behaviour of individuals in response to an increase in host density (Fernandez-Arhex \& Corely, 2003). This, is refered to as its functional response and is the relationship between the number of prey or hosts attacked by a predator or parasitoid and the population density of the prey (host). The functional response is one of the crucial factors in the dynamics of populations and communities (Solomon, 1949; Holling, 1959). Basically, there are three types of functional response (Holling, 1959). The type I response is a linear increase in host numbers attacked with increase in host population density. The relationship between the attack efficiency and host population density in the type II response is curvilinear and in the type III takes the form of a sigmoid curve (Hassell, 1978).

Temperature is one of the major abiotic factors influencing the performance of parasitoids. At high temperatures the longevity and life-time fecundity of parasitoids are reduced (Jervis \& Copland, 1996). Temperature also affects the functional response of a parasitoid, especially in the temperature range over which parasitoids search for their hosts (Gitonga et al., 2002). In recent years, the predictions of climatic warming have stimulated investigations of temperature-dependent population dynamics, an understanding of which is essential for precise implementation of pest management strategies (Fand et al., 2014). In the tropical and subtropical regions of the world, the temperature favours the spread and population increase of $P$. solenopsis. Therefore, future increases in temperature in these areas may result in an increase in the damage done by P. solenopsis (Wang et al., 2010). There are a few studies on natural parasitization and the laboratory assessment of the parasitism potential of $A$. bambawalei (Kumar et al., 2009; Ram \& Saini, 2010; Fand et al., 2011; Prasad et al., 2011; Feng et al., 2014). The only study on the functional response of A. bamawalei is that of Feng et al. (2014), which investigated the parasitism potential of this parasitoid attacking $P$. solenopsis at a constant temperature in a laboratory in China. The aim of the current study was to determine the effect of different temperatures on the functional response of A. bambawalei.

\section{MATERIALS AND METHODS}

Studies on the functional response of $A$. bambawalei were carried out in the entomology laboratory of Ramin Agriculture and Natural Resources University of Khuzestan in South-West Iran.

\section{Insect culture}

Twigs of the shrub $H$. rosa-sinensis infested with various stages of $P$. solenopsis were collected from the campus of the university in April 2016. Female mealybugs were collected from the infested twigs and released on young potato, Solanum tuberosum L., sprouts ( 0.5 to $1.5 \mathrm{~cm}$ in length) in rearing containers $(24 \times 10 \times 16 \mathrm{~cm})$ covered with fine mesh. They were allowed to settle, feed and reproduce to establish colonies of mealybugs for use in the experiments. To establish a colony of $A$. bambawalei, mummified mealybugs were collected from the same mealybug infested shrubs. About 30 mummies were placed in a separate container, each of which was kept in different incubators at either 25,30 or $35^{\circ} \mathrm{C}$, with $65 \pm 5 \%$ R.H. and $14 \mathrm{~L}: 10 \mathrm{D}$. After the adults emerged, they were collected using an aspirator and transferred to containers with potato sprouts infested with $3^{\text {rd }}$ instar nymphs of P. solenopsis. The female wasps were allowed to oviposit in the nymphs. The colonies of $P$. solenopsis and $A$. bambawalei were kept in incubators in the above mentioned conditions.

\section{Experimental design}

To determine the effect of temperature on the functional response of $A$. bambawalei, different numbers of 2, 4, 8, 16, 32 and 64 third instar nymphs of $P$. solenopsis were offered to mated females of the parasitoid ( $48 \mathrm{~h}$ old) on potato sprouts at each of the three temperatures $\left(25,30\right.$ and $\left.35 \pm 1{ }^{\circ} \mathrm{C}\right)$ at $65 \pm 5 \%$ R.H. and a $14 \mathrm{~L}: 10 \mathrm{D}$ photoperiod. The test arena was a cylindrical transparent container $(6 \mathrm{~cm}$ diameter $\times 10 \mathrm{~cm}$ height $)$. The duration of the experiment was $24 \mathrm{~h}$ and then the parasitoids were removed and the containers containing mealybug nymphs were kept in incubators at the same constant temperatures. When the mummies appeared on the potatoes, their numbers were recorded. There were ten replicates of each host density in each trial.

\section{Statistical analysis of the functional responses}

A two-way factorial analysis of variance (ANOVA) was used to determine the effects of temperature and density on the proportion of hosts parasitized by $A$. bambawalei and the interactions of the main effects using the Holm-Sidak test in Sigmaplot version 12.0 .

The analysis of the parasitoid's functional response at the different temperatures was conducted in two separate stages. In the first step, logistic regression analysis of the proportion of parasitized nymphs as a function of initial density was used to determine the type of functional response (Juliano, 2001). This is done by fitting the following polynomial function:

$$
\frac{N_{a}}{N_{0}}=\frac{\exp \left(P_{0}+P_{1} N_{0}+P_{2} N_{0}^{2}+P_{3} N_{0}^{3}\right)}{1+\exp \left(P_{0}+P_{1} N_{0}+P_{2} N_{0}^{2}+P_{3} N_{0}^{3}\right)}
$$

where $N_{a}$ is the number of parasitized hosts, $N_{0}$ is the initial number of hosts offered, and $P_{0}, P_{1}, P_{2}$ and $P_{3}$ are the parameters to be estimated. These parameters were calculated using the method of maximum likelihood (PROC CATMOD, SAS Institute 2001). The signs of $P_{1}$ and $P_{2}$ can be used to distinguish the shape of the curves. If $P_{1}$ is positive and $P_{2}$ is negative, the proportion of parasitized hosts is positively density-dependent; therefore, the data describe a type III functional response, but if $P_{1}$ is negative and $P_{2}$ is positive, the proportion of parasitized hosts decreases gradually as the initial number of prey offered increases and the data indicate a type II functional response. Type I functional response is indicated if the linear parameter $P_{1}$ is not significantly different from zero (Juliano, 2001). In the second step, nonlinear least squares regression (PROC NLIN; SAS Institute Inc., 2001) was used to fit Roger's random attack model, which describes a type II or III functional responses, for estimating the functional response parameters (Rogers, 1972; Juliano, 2001). Because host density was reduced during the trial, this model, which does not assume a constant host density, is a suitable choice for the analysis (Juliano, 2001).

Following this analysis and since our data fit a type II functional response we used the Rogers type II equation as follows:

$N_{a}=N_{0}\left\{1-\exp \left[a\left(T_{h} N_{a}-T\right)\right]\right\}$ 
where $N_{a}$ is the number of parasitized host, $N_{0}$ is the initial number of hosts, $a$ is the instantaneous searching efficiency (attack rate), $\mathrm{T}$ is the total amount time available for searching (in this experiment $\mathrm{T}=24 \mathrm{~h}$ ), $P_{t}$ the number of parasitoids, and $T_{h}$ is the handling time.

Pairwise comparisons of the parameters of functional responses for the three temperatures were performed using the indicator variable method (Juliano, 2001) as follows (eq. 3):

$0=N_{0}-N_{0} \exp \left\{\left[a+D_{a} j\right]\left\{\left[T_{h}+D_{T h} j\right] N_{a}-T\right\}\right\}-N_{a}$

where $j$ is an indicator variable that takes the value 0 for the first data set and the value 1 for the second data set. The parameters $D_{a}$ and $D_{T h}$ estimate the differences between the data sets in the values of the parameters $a$ and $T_{h}$, respectively. If these parameters are significantly different from 0 , then the two data sets differ significantly in the corresponding parameter.

The maximum frequency of attack $\left(\mathrm{T} / T_{h}\right)$, the maximum number of hosts that can be parasitized by an individual during $24 \mathrm{~h}$, was calculated using the estimated $T_{h}$ (Hassell, 2000).

Analysis of variance (ANOVA) by SPSS version 20 was used to compare number of parasitized host recorded at different host densities. Means were compared using the Least Significant Diference (LSD) test. SigmaPlot 12.0 was used to draw the curves of the number of hosts parasitized by $A$. bambawale $i$ when offered different numbers of $3^{\text {rd }}$ instar nymphs of $P$. solenopsis.

\section{RESULTS}

The results of the factorial analysis showed that temperature $(\mathrm{F}=50.315 ; d f=2,209 ; p<0.001)$ and host density $(\mathrm{F}=45.826 ; d f=6,209 ; p<0.001)$ had a significant effect on the proportion parasitized. There was also a significant interaction between temperature and host density $(\mathrm{F}=$ $133.409 ; d f=12,209 ; p<0.001)$. This significant difference was detected between $25^{\circ} \mathrm{C}$ and $35^{\circ} \mathrm{C}$ at a density of 8 and between $25^{\circ} \mathrm{C}, 30^{\circ} \mathrm{C}$ and $35^{\circ} \mathrm{C}$ at densities of 16,32 and $643^{\text {rd }}$ instar nymphs of $P$. solenopsis.

The functional response of $A$. bambawalei female to different densities of third instar nymphs of $P$. solenopsis are summarized in Table 1. According to the logistic regression analysis, females of $A$. bambawalei exhibited a type II functional response when attacking third instar nymphs of $P$. solenopsis at various temperatures, because the linear term of the equation $\left(P_{1}\right)$ was negative (Table 2 ). The mean number of parasitized nymphs increased significantly with increase in the number of host individual offered at all the temperatures tested; however, the proportion of hosts

Table 1. Means and analysis of variance (ANOVA) of the numbers of nymphs of Phenacoccus solenopsis parasitized by Aenasius bambawalei females at 25,30 and $35^{\circ} \mathrm{C}$.

\begin{tabular}{|c|c|c|c|c|c|c|}
\hline \multirow{3}{*}{$\mathrm{N}$} & \multicolumn{6}{|c|}{ Temperature } \\
\hline & \multicolumn{2}{|l|}{$25^{\circ} \mathrm{C}$} & \multicolumn{2}{|c|}{$30^{\circ} \mathrm{C}$} & \multicolumn{2}{|c|}{$35^{\circ} \mathrm{C}$} \\
\hline & Mean \pm SE & Range & Mean \pm SE & Range & Mean \pm SE & Range \\
\hline 2 & $1.80 \pm 0.13 a$ & $1-2$ & $1.80 \pm 0.13 a$ & $1-2$ & $2.00 \pm 0.00$ & $2-2$ \\
\hline 4 & $3.20 \pm 0.25 b$ & $2-4$ & $3.20 \pm 0.33 \mathrm{ab}$ & $1-4$ & $3.90 \pm 0.10 b$ & $3-4$ \\
\hline 6 & $3.60 \pm 0.52 b$ & $1-6$ & $4.30 \pm 0.39 b c$ & $2-6$ & $5.10 \pm 0.31 b$ & $3-6$ \\
\hline 8 & $4.20 \pm 0.61 \mathrm{bc}$ & $1-7$ & $5.10 \pm 0.57 c$ & $2-7$ & $6.30 \pm 0.37 c$ & $4-8$ \\
\hline 16 & $4.50 \pm 0.37 \mathrm{bc}$ & $3-6$ & $6.60 \pm 0.52 d$ & $4-10$ & $9.30 \pm 0.87 c$ & $5-14$ \\
\hline 32 & $4.00 \pm 0.57 \mathrm{bc}$ & $1-7$ & $6.70 \pm 0.57 d$ & $5-9$ & $9.50 \pm 0.83 c$ & $6-14$ \\
\hline 64 & $5.20 \pm 0.47 c$ & $3-7$ & $6.90 \pm 0.86 d$ & $4-10$ & $9.40 \pm 0.65 c$ & $6-13$ \\
\hline
\end{tabular}

Means in a column followed by the same letter are not significantly different at $5 \%$ level when tested using LSD.
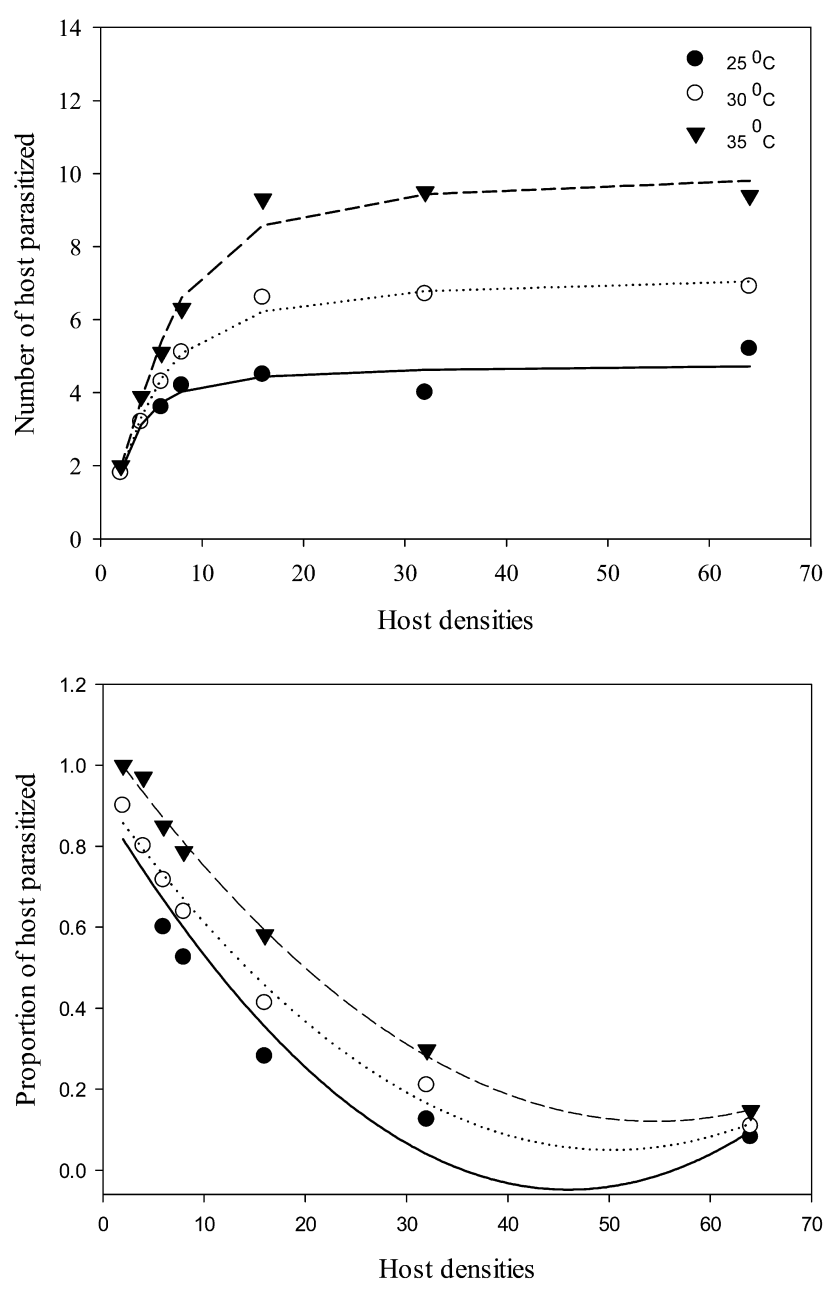

Fig. 1. Functional responses of female Aenasius bambawalei to different population densities of $3^{\text {rd }}$ instar nymphs of Phenacoccus solenopsis at 25,30 , and $35^{\circ} \mathrm{C}$. Upper figure: number of nymphs parasitized. Lower figure: proportion of nymphs parasitized. Symbols are observed results and lines are predicted by the model (eq. 2).

parasitized relative to the initial host density decreased as host density increased (Fig. 1). The Rogers' type II model was an acceptable fit to the data at all the temperature used (Table 3). The results indicated that searching efficiency changed from $0.1818 \mathrm{~h}^{-1}$ at $25^{\circ} \mathrm{C}$ to $0.1382 \mathrm{~h}^{-1}$ at $30^{\circ} \mathrm{C}$ and

Table 2. Results of the logistic regression analysis of the proportion of third instar nymphs of Phenacoccus solenopsis parasitized by Aenasius bambawalei females relative to the initial number of nymphs provided.

\begin{tabular}{|c|c|c|c|c|}
\hline$p$ & SE & Estimate & Parameters & Temperature $\left({ }^{\circ} \mathrm{C}\right)$ \\
\hline$<0.0001$ & 0.4016 & 2.2167 & Constant $\left(P_{0}\right)$ & \multirow{4}{*}{25} \\
\hline$<0.0001$ & 0.0653 & -0.3060 & Linear $\left(P_{1}\right)$ & \\
\hline 0.0036 & 0.00254 & 0.00739 & Quadratic $\left(P_{2}\right)$ & \\
\hline 0.0217 & 0.000025 & -0.00006 & Cubic $\left(P_{3}\right)$ & \\
\hline$<0.0001$ & 0.4071 & 2.2309 & Constant $\left(P_{0}\right)$ & \multirow{4}{*}{30} \\
\hline 0.0002 & 0.0627 & -0.2376 & Linear $\left(P_{1}\right)$ & \\
\hline 0.0271 & 0.00238 & 0.00526 & Quadratic $\left(P_{2}\right)$ & \\
\hline 0.0838 & 0.000024 & -0.00004 & Cubic $\left(P_{3}\right)$ & \\
\hline$<0.0001$ & 0.5497 & 3.6395 & Constant $\left(P_{0}\right)$ & \multirow{4}{*}{35} \\
\hline$<0.0001$ & 0.0760 & -0.3117 & Linear $\left(P_{1}\right)$ & \\
\hline 0.0090 & 0.00274 & 0.00716 & Quadratic $\left(P_{2}\right)$ & \\
\hline 0.0334 & 0.00026 & -0.00006 & Cubic $\left(P_{3}\right)$ & \\
\hline
\end{tabular}


Table 3. Estimated parameters of the type II functional response of Aenasius bambawalei females parasitizing third instar nymphs of Phenacoccus solenopsis.

\begin{tabular}{|c|c|c|c|c|c|c|c|}
\hline \multirow{2}{*}{$\mathrm{R}^{2}$} & \multirow{2}{*}{$\mathrm{T} / \mathrm{Th}$} & \multicolumn{3}{|c|}{ otic 95\% Cl Asymptotic } & \multirow{2}{*}{$\begin{array}{l}\text { Esti- } \\
\text { mate }\end{array}$} & \multirow{2}{*}{$\begin{array}{l}\text { Para- } \\
\text { meters }\end{array}$} & \multirow{2}{*}{$\begin{array}{c}\text { Temp. } \\
\left({ }^{\circ} \mathrm{C}\right)\end{array}$} \\
\hline & & Upper & Lower & SE & & & \\
\hline \multirow{2}{*}{0.875} & \multirow{2}{*}{4.8} & 0.3439 & 0.0197 & 0.0812 & 0.1818 & $a$ & \multirow{2}{*}{25} \\
\hline & & 5.6649 & 4.3375 & 0.3326 & 5.0012 & $T_{h}$ & \\
\hline \multirow{2}{*}{0.911} & \multirow{2}{*}{7.3} & 0.2165 & 0.0599 & 0.0393 & 0.1382 & $a$ & \multirow{2}{*}{30} \\
\hline & & 3.6617 & 2.8997 & 0.1909 & 3.2807 & $T_{h}$ & \\
\hline \multirow{2}{*}{0.943} & ก? & 0.3364 & 0.0831 & 0.0635 & 0.2097 & $a$ & \multirow{2}{*}{35} \\
\hline & 10.2 & 2.5887 & 2.1382 & 0.1129 & 2.3635 & $T_{h}$ & \\
\hline
\end{tabular}

$0.2097 \mathrm{~h}^{-1}$ at $35^{\circ} \mathrm{C}$. The handling times were calculated to be $5.0012 \mathrm{~h}, 3.2807 \mathrm{~h}$ and $2.3635 \mathrm{~h}$, at 25,30 and $35^{\circ} \mathrm{C}$, respectively. The handling rate, which is the ratio of total exposure time to the handling time (Hassell, 1978), is the theorical maximum number of host parasitized per parasitoid female per day. In this study, the handling rate increased from 4.8 to 10.2 with increase in temperature from 25 to $35^{\circ} \mathrm{C}$ (Table 3 ). The results for the comparison of type II functional response parameters showed that the three estimated values of $D_{T h}$ were significantly different from 0 and the handling time of $A$. bambawalei decreased significantly when the temperature increased from 25 to $35^{\circ} \mathrm{C}$. However, the estimated values for $D_{a}$ were not significantly different from zero.

\section{DISCUSSION}

The present study showed that the number of third instar nymphs of $P$. solenopsis parasitized by $A$. bambawale $i$ increased with increase in host density and temperature. These results also indicate that the optimum temperature for maximum parasitization was around $35^{\circ} \mathrm{C}$. The average number of $P$. solenopis nymphs parasitized by $A$. bambawalei females was 1.8 at a density of 2 nymphs and $25^{\circ} \mathrm{C}$ and reached a maximum of 9.4 at a density of 64 nymphs and $35^{\circ} \mathrm{C}$. Zhang et al. (2016) investigated the effects of different temperatures $\left(21^{\circ} \mathrm{C}, 24^{\circ} \mathrm{C}, 27^{\circ} \mathrm{C}, 30^{\circ} \mathrm{C}, 33^{\circ} \mathrm{C}\right.$, $36^{\circ} \mathrm{C}$ and $39^{\circ} \mathrm{C}$ ) on the parasitization of $P$. solenopsis by $A$. bambawale $i$ and noted that the perecentage parasitization increased with increase in temperature and peaked at $36^{\circ} \mathrm{C}$, which is very similar to our result. However, Zhang et al. (2016) report higher parasitization of adult females of $P$. solenopsis than third instar nymphs after $24 \mathrm{~h}$ of exposure. The current study was done using only third instar nymphs as hosts, so it is not comparable to Zhang et al. study in this respect.

The parasitoid also showed a type II functional response at all the temperatures tested. There is no other study on the functional response of $A$. bambawalei attacking cotton mealybug at a range of temperatures suitable for its survival and development. These results are consistent with the finding of a previous study by Feng et al. (2014), which report a Holling's Type II response for $A$. bambawalei attacking third instar nymphs of $P$. solenopsis at $27 \pm 1{ }^{\circ} \mathrm{C}$, relative humidity of $70 \pm 5 \%$ and a photoperiod of $12 \mathrm{~L}$ : 12D. Several researchers have also studied the effects of constant temperature on the functional response of parasitoids of different species of mealybugs (Flinn, 1991; Joens et al., 2003; Zamani et al., 2006). Similarly, Chong \& Oetting (2006) report a type II functional response for Anagyrus sp. near sinope Noyes \& Menezes attacking Phenacoccus madeirensis Green. Similarly, Bugila (2014) report a type II response for Anagyrus sp. near pseudococci (Girault) attacking Pseudococcus calceolariae (Maskell), whereas for Planococcus ficus (Signoret) a type III model is a better description of the response of this parasitoid.

Functional responses are usually considered to be an important factor in the selection of the most suitable biocontrol agents. Type II functional response is theoretically less capable of suppressing host density compared to the type III functional response (Holling, 1965). Although reviews indicate that the type II functional response is more frequently recorded for parasitoids and type III is not prevalent in parasitic insects, the form of the functional response on its own does not determine the success or failure of parasitoids in biological control (Fernandez-Arhex \& Corely, 2003). Other factors like numerical response, intrinsic growth rates, host patchiness, and competition (Pervez, 2005), as well as abiotic and biotic environmental factors such as habitat heterogeneity (Lipcius \& Hines, 1986), temperature (Mahdian et al., 2006; Jalali et al., 2010), host plant (Salehi et al., 2016) and light (Koshi \& Johnson, 2002) also affect the efficacy of natural enemies in pest management.

In the current study, temperature affected the magnitude of the parasitoid response to host density (Fig. 1). Both handling time and searching efficiency varied in response to temperature. Although the search rate of $A$. bambawalei increased with temperature, the differences were not significant. However, there was a significant decrease in handling time with increase in temperature, which means that at high temperatures there is more time available for searching and a greater probability of finding more hosts. Similar findings are reported by Flinn (1991), Menon et al. (2002), Jones et al. (2003), Zamani et al. (2006) and ZandiSohani et al. (2008).

Laboratory studies on functional responses may be considered to be unrealistic as in the field the size and area parasitoids have to search for hosts, host plants and weather vary greatly (O’Neil, 1989; Kareiva, 1990). However, such studies are useful as they provide primary information on parasitoid efficiency. Additional parameters such as the numerical response and interference competition must be considered when evaluating $A$. bambawalei as a potential biological control agent of $P$. solenopsis and should be included in future investigations.

ACKNOWLEDGEMENTS. The authors wish to thank the Khuzestan Agricultural Sciences and Natural Resources University, Iran for financial support of this research project.

\section{REFERENCES}

Bodlah I., Ahmad M., Faroq Nasir M. \& Naeem M. 2010: Record of Aenasius bambawalei Hayat, 2009 (Hymenoptera: Encyrtidae), a parasitoid of Phenacoccus solenopsis (Sternorrhyncha: Pseudococcidae) from Punjab, Pakistan. - Pakist. J. Zool. 42: 533-536. 
Bugila A.A.A. 2014: Host-parasitoid Relationships of Anagyrus sp. near pseudococci (Girault), (Hymenoptera, Encyrtidae), as a Basis to Improve Biological Control of Pest Mealybugs (Hemiptera, Pseudococcidae). PhD Thesis, University of Lisbon, $102 \mathrm{pp}$.

Chong J.H. \& Oetting R.D. 2006: Functional response and progeny production of the Madeira mealybug parasitoid, Anagyrus sp. nov. nr. sinope: The effect of host stage preference. - Biol. Contr. 39: 320-328.

Fand B.B., Gautam R.D. \& Suroshe S.S. 2011: Suitability of various stages of mealybugs, Phenacoccus solenopsis (Homoptera: Psudococcidae) for development and survival of the solitary endoparasitoid, Aenasius bambawalei (Hymenoptera: Encyrtidae). - Biocontr. Sci. Tech. 21: 51-55.

Fand B.B., Tonang H.E.Z., Kumar M. \& Kamble A.L. 2014: A temperature-based phenology model for predicting development, survival and population growth potential of the mealybug, Phenacoccus solenopsis Tinsley (Hemiptera: Pseudococcidae). - Crop Prot. 55: 98-108.

Feng D.D., Li P., Zhou Z.-S., Xu Z.-F. 2014: Parasitism potential of Aenasius bambawalei on the invasive mealybug Phenacoccus solenopsis. - Biocontr. Sci. Tech. 24: 1333-1338.

Fernandez-Arhex V. \& Corely J. 2003: The functional response of parasitoids and its implication for biological control. - Biocontr. Sci. Tech. 13: 403-413.

FLINN P.W. 1991: Temperature-dependent functional response of the parasitoid Cephalonomia waterstoni (Gahan) (Hymenoptera: Bethylidae) attacking rusty grain beetle larvae (Coleoptera: Cucujidae). - Environ. Entomol. 20: 872-876.

Gitonga L.M., Overholt W.A., Lohr B., Magambo J.K. \& Mueke J.M. 2002: Functional response of Orius albidipennis (Hemiptera: Anthocoridae) to Megalurothrips sjostedti (Thysanoptera: Thripidae). - Biol. Contr. 24: 1-6.

Hassell M.P. 1978: The Dynamics of Arthropod Predator-Prey Systems. Princeton University Press, Princeton, 248 pp.

Hassell M.P. 2000: The Spatial and Temporal Dynamics of Host Parasitoid Interactions. Oxford University Press, London, 212 pp.

HolLING C.S. 1959: Some characteristics of simple type of predation and parasitism. - Can. Entomol. 91: 358-398.

Holling C.S. 1965: The functional response of the predators to prey density and its role in mimicry and population regulation. - Mem. Entomol. Soc. Can. 45: 1-60.

Hodgson C., Abbas G., Jalal M.J., Saeed S. \& Karar H. 2008: Phenacoccus solenopsis Tinsley (Sternorrhyncha: Coccoidea: Pseudococcidae), an invasive mealybug damaging cotton in Pakistan and India, with a discussion on seasonal morphological variation. - Zootaxa 1913: 1-35.

Jalali M.A., Tirry L. \& De ClercQ P. 2010: Effect of temperature on the functional response of Adalia bipunctata to Myzus persica. - Biocontrol 55: 261-299.

Jervis M.A. \& Copland M.J.W. 1996: The life cycle. In Jervis M.A. \& Kidd N. (eds): Insect Natural Enemies: Practical Approaches to their Study and Evaluation. Chapman and Hall, London, pp. 63-161.

Jones D.B., Giles K.L., Berberet R.C., Royer T.A., Elliott N.C. \& PAyton M.E. 2003: Functional responses of an introduced parasitoid and an indigenous parasitoid on greenbug at four temperatures. - Environ. Entomol. 32: 425-432.

JuLIANO S.A. 2001: Non-linear curve fitting: predation and functional response curves. In Scheiner S.M. \& Gurevitch J. (eds): Design and Analysis of Ecological Experiments. 2nd ed. Chapman and Hall, New York, pp. 178-196.
KAREIVA P. 1990: The spatial dimension in pest-enemy interaction. In Mackauer M., Ehler L.E. \& Roland J. (eds): Critical Issues in Biological Control. Intercept, Anover, Hants, pp. 213-227.

Koshi M.L. \& Johnson B.M. 2002: Functional response of Kokanee salmon (Onchorynchus nerka) to Daphnia at different light levels. - Can. J. Fish. Aquat. Sci. 59: 707-716.

Kumar R., Kranthi K.R., Monga D. \& Jat L. 2009: National parasitization of Phenacoccus solenopsis Tinsley (Hemiptera: Pseudococcidae) on cotton by Aenasius bambawalei Hayat (Hymenoptera: Encyrtidae). - J. Biol. Contr. 23: 457-460.

LipCIUS R.N. \& Hines A.H. 1986: Variable functional responses of a marine predator in dissimilar homogeneous microhabitats. Ecology 67: 1361-1371.

Mahdian K., Vantornhout I., Tirry L. \& De Clerce P. 2006: Effects of temperature on predation by stinkbugs Pivromerus bidens and Podisus maculiventris (Heteroptera: Pentatomidae) on noctuid caterpillars. - Bull. Entomol. Res. 96: 489-496.

Menon A., Flinn P.W. \& Dover B.A. 2002: Influence of temperature on the functional response of Anisopteromalus calandrae (Hymenoptera: Pteromalidae), a parasitoid of Rhyzopertha dominica (Coleoptera: Bostrichidae). - J. Stored Prod. Res. 38: 463-469.

Moghadam M. \& Bagheri A.N. 2010: A new record of mealybug pest in south of Iran. Phenacoccus solenopsis (Hemiptera: Coccoidea: Pseudococcidae). - J. Entomol. Soc. Iran 30: 67-69.

Mossadegh M.S., Vafaei S., Farsi A., Zarghami S., Esfandiari M., Dehrordi F.S., Fazelinejad A. \& Seyfollahi F. 2015: Phenacoccus solenopsis Tinsley (Sternorrhyncha: Pseudococcidae), its natural enemies and host plants in Iran. In: Proc. of the $1^{\text {st }}$ Iranian International Congress of Entomology, 29-31 August. Iranian Research Institute of Plant Protection, Tehran, pp. 251-259.

O’NeIL R.J. 1989: Comparison of laboratory and field measurments of the functional response of Podisus maculiventris (Heteroptera: Pentatomidae). - J. Kans. Entomol. Soc. 70: 40-48.

Pervez A. 2005: Functional responses of coccinellid predators: an illustration of a logistic approach. - J. Insect Sci. 5: 1-6.

Prabhakar M., Prasad Y.G., Vennila S., Thirupathi M., Sreedevi G., Rao G.R. \& Venkateswarlu B. 2013: Hyperspectral indices for assessing damage by the solenopsis mealybug (Hemiptera: Pseudococcidae) in cotton. - Comput. Electron. Agr. 97: 61-70.

Prasad Y.G., Prabhakar M., Sreedevi G. \& Thirupathi M. 2011: Spatio-temporal dynamics of the parasitoid, Aenasius bambawalei Hayat (Hymenoptera: Encyrtidae) on mealybug, Phenacoccus solenopsis Tinsley in cotton based cropping systems and associated weed flora. - J. Biol. Contr. 25: 198-202.

RAM P. \& SAINI P.K. 2010: Biological control of solenopsis mealybug, Phenacoccus solenopsis Tinsley on cotton: a typical example of fortuitous biological control. - J. Biol. Contr. 24: 104-109.

Rogers D. 1972: Random search and insect population models. - J. Animal Ecol. 41: 369-383.

Salehi S., Yarahmadi F., Rasekh A. \& Zandi Sohani N. 2016: Functional response of Orius albidipennis Reuter (Hemiptera, Anthocoridae) to Tuta absoluta Meyrick (Lepidoptera, Gelechidae) on two tomato cultivars with different leaf morphological characteristics. - Entomol. Gener. 36: 127-136.

ShISHEHBor P. \& ZANDI-SoHANI N. 2011: Investigation on functional and numerical responses of Encarsia acaudaleyrodis parasitizing Bemisia tabaci on cucumber. - Biocontr. Sci. Technol. 21: 271-280

Solomon J.E. 1949: The natural control of animal populations. J. Anim. Ecol. 18: 1-35. 
Tanwar R.K., Jeyakumar P., Singh A., Jafri A.A., Bambawale O.M. 2011: Survey for cotton mealybug, Phenacoccus solenopsis (Tinsley) and its natural enemies. - J. Environ. Biol. 32: 381-384.

Wang Y., Watson G.W. \& Zhang R. 2010: The potential distribution of an invasive mealybug Phenacoccus solenopsis and its threat to cotton in Asia. - Agr. For. Entomol. 12: 403-416.

Williams D.J. \& Granara De Willink M.C. 1992: Mealybugs of Central and South America. CAB International, Wallingford, $635 \mathrm{pp}$.

Zamani A.A., Talebi A.A., Fathipur Y. \& Baniameri V. 2006: Temperature-dependent functional response of two aphid parasitoids, Aphidius colemani and Aphidius matricariae (Hy- menoptera: Aphidiidae) on cotton aphid. - J. Pest Sci. 79: $183-188$.

Zandi-Sohani N., Shishehbor P. \& Kocheili F. 2008: Functional and numerical responses of Eretmocerus mundus Mercet (Hymenoptera: Aphelinidae) parasitizing cotton whitefly Bemisia tabaci Genndius (Homoptera: Aleyrodidae). - Pakist. J. Biol. Sci. 11: 1015-1020.

Zhang J., Huang J., Lu Y. \& Xia T. 2016: Effects of temperature and host stage on the parasitization rate and offspring sex ratio of Aenasius bambawalei Hayat in Phenacoccus solenopsis Tinsley. - Peer J. 4: e1586, 13 pp.

Received January 20, 2018; revised and accepted May 15, 2018 Published online July 9, 2018 